Philipp Rüppell

\title{
Die Berücksichtigungsfähigkeit ausländischer Anlagengenehmigungen
}

Eine Analyse im Rahmen der grenzüberschreitenden Umwelthaftung nach der Rom II-Verordnung

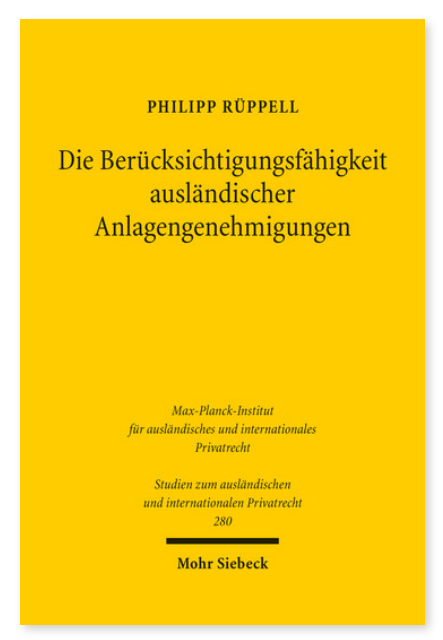

2012. XXV, 271 Seiten. StudIPR 280

ISBN 978-3-16-152166-9

eBook PDF 74,00€

ISBN 978-3-16-151911-6

fadengeheftete Broschur 74,00€
Ein wichtiges Instrument zum Ausgleich von Umweltschädigungen sind die Abwehr-, Unterlassungs- und Schadensersatzansprüche der zivilrechtlichen Umwelthaftung. Bei grenzüberschreitenden Umweltschädigungen können diese Ansprüche verschiedenen Hindernissen begegnen. Philipp Rüppell hinterfragt, wie Gerichte mit ausländischen Anlagengenehmigungen verfahren und wie sie von einer ausländischen Rechtsordnung angeordnete Ausschlüsse bewerten. Das Thema ist sowohl durch die neuen kollisionsrechtlichen Regelungen der Verordnung über das auf außervertragliche Schuldverhältnisse anzuwendende Recht (»Rom Il«) als auch durch eine junge Entscheidung des Europäischen Gerichtshofs zur Atomhaftung (Oberösterreich ./. ČEZ) in Bewegung gekommen. Der Autor entwickelt einen neuen Lösungsansatz aus den die Umwelthaftung betreffenden Bestimmungen der Rom II-VO (Art. 7 und 17) und den völkerrechtlichen Vorgaben für Planungsverfahren aus den UNECE-Konventionen (Espoo und Aarhus) und deren Umsetzungen.

Philipp Rüppell Geboren 1978; Studium der Rechtswissenschaften in Passau, London und Würzburg; Referendariat beim Hanseatischen Oberlandesgericht in Hamburg mit Stationen in New York und Brüssel; Rechtsanwalt für Prozessführung im Hamburger Büro einer US-amerikanischen Law Firm.

Jetzt bestellen:

https://mohrsiebeck.com/buch/die-beruecksichtigungsfaehigkeit-auslaendischer-anlagengenehmigungen-9783161521669? no_cache=1

order@mohrsiebeck.com

Telefon: +49 (0)7071-923-17

Telefax: +49 (0)7071-51104 